\title{
Physical indicators for pollution detection in terrestrial and aquatic ecosystems
}

\author{
Alaa Zaghloul $^{*}$ (D), Mohamed Saber and Mohamed Abd-El-Hady
}

\begin{abstract}
Background: Soil indicators are commonly used to evaluate and give an idea how well soil functions since soil function often cannot be directly measured. Measuring soil quality is an exercise in identifying soil properties that are responsive to management, affect or correlate with environmental outcomes, and are capable of being precisely measured within certain technical constraints.

Results: Physical pollution indicators are numerical values supporting tangible perception on the state of a given aquatic or terrestrial ecosystem. Physical pollution indicators track qualitative and quantitative changes over time. Most of the physical pollution indicators are applicable in a wide variety of ecosystems from local to regional to national levels. They include temperature, color, odor, aggregate stability, available water capacity, bulk density, infiltration rate, slaking, crusts, structure, and macro-pores. Only, the most distinct and reliable physical pollution indicators with the actual wide practice were designated.
\end{abstract}

Keywords: Physical parameters, Pollution, Aquatic ecosystems, Terrestrial ecosystem

\section{Introduction}

Pollution is known as any undesirable changes in the physical, chemical, and/or biological features of a given ecosystem. It is now considered as a major challenge facing the global society. Biological, chemical, and physical pollution indicators are classified as descriptive, performance, efficiency, policy effectiveness, and total welfare ones. However, recording all variable in a given ecosystem necessitates the amalgamating of biological, chemical, and physical pollution indicators.

Physical pollution indicators are measurements that tell about what is happening in a given ecosystem. They are designed to translate complex information in a concise and easily understood manner in order to describe a particular ecosystem.

An ideal physical pollution indicator should be well allied to ecosystem processes, integrated with its physical, chemical, and biological properties, accessible to many users, sensitive to changes, interpretable and provide true measures of a given ecosystem. Some physical pollution indicators are descriptive and are used in the field others are measured at the laboratory.

\footnotetext{
* Correspondence: alaazaghoul2008@gmail.com

Agricultural and Biological Division, Soils and Water Use Department, National Research Centre, P.O. Box 12622, Giza, Egypt
}

The aim of the current work is to through light on significance of physical pollution indicators in the sound management of ecosystem tribulations. The most significant physical pollution indicators were provided below.

\section{Physical pollution indicators for aquatic ecosystems}

The quality of a given aquatic ecosystem affects not only biotas but also the whole surroundings as well and is an imperative part of the whole environmental monitoring. In most cases, the quality of aquatic ecosystems is determined through physical, chemical, and biological pollution indicators. Such indicators are characterized by wide variability. Therefore, estimating the quality of natural aquatic ecosystem should be established in terms of the specific water-quality parameters that most affect the possible uses of water. Following are definitions of each indicator, where it comes from and why it is important to measure. The most significant and habitually used physical pollution indicators are color, taste, and odor,

\section{Soil color}

In natural aquatic ecosystems, color is ascribed to the existence of humic acids, fulvic acids, metallic ions, suspended matter, plankton, weeds, and industrial effluents. 
Color is determined by visual comparison of each sample with distilled water. For visual comparison, about 20 $\mathrm{ml}$ of the water sample and $20 \mathrm{ml}$ of distilled water are collected in two separate wide-mouthed test tubes (Geisseler et al. 2011). The results are described as clear, greenish, grayish, brownish, blackish, etc. in comparison with distilled water.

Color is of primary concern in water quality for several esthetic reasons. Colored water gives the appearance of being unfit to drink, even though the water might be perfectly safe for other public uses. On the other hand, the color might indicate the presence of organic substances, such as algae or humic compounds. More recently, had been used as a quantitative assessment indicator for the presence of potentially hazardous or toxic organic materials in aquatic ecosystems.

In natural non-polluted aquatic ecosystems, water is colorless and transparent. Shallow aquatic ecosystems should be colorless, while being light green or blue in deep ones. The existence of humus, terrestrial ecosystem, plankton, iron and manganese, and other metal ions in natural aquatic ecosystems shades water with colors. Effluent disposal generating from textile, printing and dyeing, paper making, and food, organic synthesis industries in aquatic ecosystems enrich them with dyes, biological pigments, and colored suspended particles. Colored aquatic ecosystems often gave a sense of unhappiness, reduce light transmission in the water body, and affect the growth of aquatic biotas.

\section{Taste and odor}

Taste and odor are human perceptions, i.e., sour (hydrochloric acid), salty (sodium chloride), sweet (sucrose), and bitter (caffeine), of aquatic ecosystems quality. In general, the existence of simple compounds in aquatic ecosystems generate sour and salty tastes. However, sweet and bitter tastes are made by more complex organic compounds. Human can detect many types of odor than of tastes. Organic pollutants reaching aquatic ecosystems are the main sources of tastes together with odor-producing pollutants released during biodegradation. In odorless and tasteless aquatic ecosystems, however, pollutants' absence could not even be ensured. Most organic and inorganic pollutants in aquatic ecosystems come mainly from disposing of domestic and industrial effluents, decomposition of natural materials, and/or biotas activities. Some pollutants, existing in aquatic ecosystems, could easily be detected. Yet, it is not that easy to determine the composition of the nastycolored and tasteful pollutants.

\section{Temperature}

The most common physical assessment of a given ecosystem is the measurement of its temperature. Impinging solar radiation and atmospheric temperature bring about spatial and temporal stratification in ambient temperature. Aquatic ecosystem temperature normally fluctuates diurnally by between day and night and seasonally over longer time periods. The temperature of surface aquatic ecosystem normally ranges between $0{ }^{\circ} \mathrm{C}$ and $30^{\circ} \mathrm{C}$, although it might exceed $40^{\circ} \mathrm{C}$ in hot seasons. Chemical and biological reaction rates always increase with increasing temperature. Reaction rates are usually assumed to double for an increase in temperature of $10{ }^{\circ} \mathrm{C}$. Temperature plays a very important role in the vitality of aquatic ecosystems affecting various parameters such as their alkalinity, salinity, and electrical conductivity. In a given aquatic ecosystem, such parameters, e.g., $\mathrm{O}_{2}$ solubility of oxygen, carbon dioxide $\mathrm{CO}_{2}$, dissolved oxygen $\mathrm{DO}$, biochemical oxygen demand (BOD), chemical oxygen demand (COD), carbonate-bicarbonate equilibrium, biotas metabolism, and physiological reactions of biotas, affect many chemical and biological reactions linked with existence of pollutants. The temperature of aquatic affects some of the important physical properties and characteristics of aquatic ecosystems, e.g., thermal capacity, density, specific weight, viscosity, surface tension, specific conductivity, salinity, and solubility of dissolved gases.

Temperature affects the solubility and reaction rates of pollutants in a given ecosystem. Rate of chemical reactions and biotas activities increases with increasing temperature. For biotas pollutants, temperature affects their metabolism, growth, reproduction, photosynthesis, sensitivity to pollutants, and pollutants species composition. Many biotas species survive only within a limited temperature range.

Thermal pollution in aquatic ecosystems arises from the introduction of water is warmer than the temperature of the body of the aquatic ecosystem into which it flows. This, in general, mainly occurs near power plants and some industries. Other source of thermal pollution is urban runoff. Plowing near ecosystem streams or removal of the forest canopy during construction also contributes to thermal pollution by decreasing shade, thereby increasing solar heating of the ecosystem surface. Further, to increase solar radiation reaching the aquatic ecosystem surface, the removal of vegetation often increases erosion and increases sediments that absorb heat from sunlight rather than reflecting it in ecosystems. Low DO level is magnified by biotas metabolism that increases parallel to temperature rise, thus increasing their BOD.

When the temperature is outside the optimal range, pollutant biotas are stressed and might die. Worthy to state that reproductive stage in fish, for instance, including spawning and embryo development is the most temperature-sensitive period. Macroinvertebrates such as insects, crayfish, worms, clams, and snails would 
move to the stream bed to find their optimal temperature.

\section{Transparency}

Transparency is a characteristic of aquatic ecosystems that varies with the combined effect of color and turbidity. It measures the light penetrating through the aquatic ecosystem body and is determined using Secchi disc. In a given aquatic ecosystem, transparency serves as a basic physical pollution indicator. Under lower flow conditions in small aquatic ecosystems, transparencies could indicate certain aquatic ecosystem pollution problems.

Transparency contrary to turbidity refers to the clarity of the water in a given aquatic ecosystem. Clean water is transparent, however, the more suspended solids in aquatic ecosystems, the lower its transparency will be. During lower flows, transparency reflects high levels of free-floating algae in the water or fine pollution sediments that remain in suspension for an extended time. Excellent transparency aquatic ecosystems are likely to have excellent water quality.

Based on the correlation coefficients between mean zooplankton abundance and physical pollution parameters, water transparency exhibited a strong significant negative correlation $(p<0.05)$ with zooplankton abundance. This is good evidence that eutrophication alters water transparency and has the potential to affect zooplankton community dynamics.

\section{Total suspended solids}

The total solids content in aquatic ecosystems is defined as the residue remaining after evaporation of the aquatic ecosystems water and drying the residue to a constant weight from $103{ }^{\circ} \mathrm{C}$ to $105^{\circ} \mathrm{C}$. The organic fraction of volatile solids, on the other hand, is lost in the residue weight remaining after evaporation of the aquatic ecosystem water and ignition at $500{ }^{\circ} \mathrm{C}$. The volatile solids are oxidized at this temperature and driven off as gas. Left inorganic solids remain as inert ash. They are classified as settleable, suspended, or filterable. Settleable solids (silt and heavy organic solids) settle under the influence of gravity (Hasan et al. 2011). Suspended solids and filterable solids are classified on the basis of their particle size and retention of suspended solids on standard glass-fiber filters. Aquatic ecosystems with high-suspended solids are considered polluted and hence unsatisfactory for many purposes.

\section{Turbidity}

Like transparency, turbidity is a physical indicator of aquatic ecosystems pollution, i.e., the more particles suspended matter in a given aquatic ecosystem, the more the pollution intensity. Certainly, the measurement of turbidity is key test pollution in aquatic ecosystems.
Because transparency values reliably predict turbidity, i.e., low transparency represents high turbidity. High TSS or the presence of dark-colored humic acids in a given aquatic ecosystem would result in high turbidity. Suspended solids are varied, ranging from clay, silt, and plankton to industrial and sewage effluent. When turbidity is high, aquatic ecosystems loses its ability to support a diversity of biotas. Also, $\mathrm{O}_{2}$ levels decrease in turbid aquatic ecosystemss as they become warmer as the result of heat absorption from the sunlight by the suspended particles and with decreased light penetration resulting in decreased photosynthesis; therefore, when turbidity is high, a possible bacterial pollution is expected. The most widely used measurement unit for turbidity is formazin turbidity units (FTU). Turbidity measured this way uses an instrument called a nephelometer. Aquatic ecosystems quality measurements that help in the characterization of turbidity include total suspended solids, volatile suspended solids, total dissolved solids, suspended sediment concentration, chlorophyll A, and particle size analysis. Other factors such as flow, sediment source and composition, algal species, and sediment transport characteristics could also provide important information in characterizing the turbidity present in aquatic ecosystems. High levels of suspended sediment often create negative effects on aquatic biotas. For instances, high turbidity means higher concentrations pollutants. Therefore, any sudden changes in turbidity might indicate the presence of a new pollution source (biological, organic, or inorganic) in natural aquatic ecosystemss.

Turbidity itself does not always represent a direct risk to pollutants; however, it indicates the existence of pathogenic biotas and is considered an effective indicator of hazardous events throughout the aquatic ecosystems. Generally, turbidity affects light scattering, absorption properties, and esthetic appearance in aquatic ecosystems. Increase in the intensity of scattered light results in higher values of turbidity.

\section{Conductivity}

Conductivity refers to the total amount of inorganic mineral compositions contained in a given aquatic ecosystem. Conductivity is an important physical pollution indicator determining the chemical compositions of aquatic ecosystems and is used also in the evaluation of their irrigation applicability. Conductivity is commonly used in the evaluation of aquatic ecosystems quality and is mainly expressed as the sum of the mass of major ions tested. The conductivity of pure aquatic ecosystems water is very low, but when the aquatic ecosystems contain inorganic acid, alkali, or salt, their conductivity increase. The conductivity of any aqueous solution depends on its nature, concentration of ions, 
temperature, and viscosity and varies with temperature. Each increase of one degree in temperature virtually raises the conductivity by nearly $2 \%$. Conductivity measures the electrical conductance in aquatic ecosystems is an indication of the quantity of dissolved inorganic acids, bases, and salts in a given aquatic ecosystem.

\section{Physical pollution indicators for terrestrial ecosystems}

Measuring terrestrial ecosystem pollution status is a major exercise for identifying their properties responsive to their management, their correlations with other environmental outcomes, and their capabilities of being precisely measured within certain technical and economic constraints. Qualitative and quantitative physical pollution indicators are habitually used to evaluate how well a given terrestrial ecosystem functions. No doubt, a combined approach using all physical, chemical, and biological pollution indicators in assessing terrestrial ecosystem pollution is much better than using a single attribute. In general, a terrestrial ecosystem is considered physically polluted when it exhibits low rates of water infiltration, enhanced surface runoff, poor cohesion, low aeration, and root density, and difficulty for mechanization.

Physical pollution indicators are always correlated with certain hydrological processes like erosion, aeration, runoff, infiltration rate, and water holding capacity (Schoenholtz et al. 2000). They are generally simple, fast, and low-cost. They include the estimation of aggregate slaking, texture, aggregation, moisture, porosity, and bulk density. Dexter (2004) stated that a terrestrial ecosystem is considered physically poor when it exhibits low rates of water infiltration, enhanced surface runoff, poor cohesion, low aeration and root density, and difficulty for mechanization.

\section{Texture}

Terrestrial ecosystem texture is an important physical pollution indicator affecting the balance between water and gases (Qin, et al. 2010), yet it is very stable over time, independently on terrestrial ecosystems management.

\section{Structure}

The structure corresponds to the arrangement of the primary terrestrial ecosystem particles (sand, silt, and clay) and is mainly affected by pollutants and compaction (Dexter 2004). Organic pollutants and biotas shape the terrestrial ecosystem physical structure and consequently its hydrological processes.

\section{Aggregate slaking}

Slaking refers to the process in which earth materials are disintegrated and crumbled when exposed to moisture.
Microaggregates $(20-250 \mu \mathrm{m})$ are formed from particles smaller than $0.2 \mu \mathrm{m}$. They are more stable and less affected by water use and management and responsible for long-term stabilization of organic carbon (Six et al. 2004). Macroaggregates, on the other hand, are more susceptible to water uses and management and are especially related to the dynamics of organic matter (Six et al. 2004). Any decrease in organic matter following dispersion of aggregates reduces the macroporosity and oxygenation and impairs the performance of decomposing microbiotas and their access to the organic material (Degens et al. 2000; Tejada et al. 2006; Chodak and Niklinska 2010). Many organic substances produced by fauna, arbuscular mycorrhizal fungi, bacteria, and plants as secretions, mucilages, mucigels, and/or cell lysates act as cementing material and stimulate aggregates formation (Preston et al. 2001). Organic matter and biological attributes shape the structure and hydrological processes, i.e., erosion, drainage, runoff, and infiltration rate. Humic substances increase the capacity for water retention due to charges in their carboxylic and phenolic groups which attract the water molecule and thus reduce its percolation through terrestrial ecosystem profile. Terrestrial ecosystem physical pollution indicators might be qualitative (e.g., drainage is fast) or quantitative (infiltration $=2.5 \mathrm{in} / \mathrm{h}$ ).

\section{Bulk density}

Bulk density of terrestrial ecosystem depends greatly on their mineral makeup and the degree of compaction. Despite the density of quartz is nearly $2.65 \mathrm{~g} / \mathrm{cm}^{3}$ yet the bulk density of a terrestrial ecosystem is less than half that density. Most teresterial ecosystems have a bulk density between 1.0 and $1.6 \mathrm{~g} / \mathrm{cm}^{3}$ while organic terrestrial ecosystem and some friable clay might have a bulk density well below $1 \mathrm{~g} / \mathrm{cm}^{3}$. The more the pore space in a terrestrial ecosystem the low value of bulk density. Bulk density together with total porosity could better represent a terrestrial ecosystem use and management through water/air relationships. Bulk density and total porosity are considered physical pollution indicators in terrestrial ecosystems particularly in relation to their hydrological characters (Beutler et al. 2002). Lower bulk densities had been repeatedly noticed in some forest terrestrial ecosystems (Bini et al. 2013), where the greater levels of terrestrial ecosystem organic matter permit a better aggregation of terrestrial cosystem particles, improving their structure.

\section{Porosity}

Porosity is a measure of the total pore space in a given terrestrial ecosystem. It is measured as a volume or percent. The amount of porosity depends on the minerals that make up the terrestrial ecosystem and the amount 
of sorting that occurs within its structure. For example, a sandy terrestrial ecosystem would have larger porosity than a silty sand one, because silt would fill in the gaps between the sand particles. According to Tejada et al. (2006), macro-porosity improved the terrestrial ecosystem permeability not only for water but also for air and roots. The total porosity in a given terrestrial ecosystem is classified as textural depending on the proportion of particles and structural depending on bio-pores and as macro-structure. The second one is easily affected by terrestrial ecosystem pollution and management that might change the water retention curve on the basis of structural pores (Dexter 2004). Granular structure is the most suitable for plant growth, allowing for a better balance between macro- and micro-pores, and consequently, between the air/water proportion. The structure is the major terrestrial ecosystem physical attribute affected by organic pollutants, and as a consequence, other physical characteristics such as porosity, bulk density, aeration, water infiltration, and retention.

\section{Infiltration}

Infiltration is the process by which surface water enters the terrestrial ecosystem. Water enters the terrestrial ecosystem through the pores by the forces of gravity and capillary action. The largest cracks and pores offer a great reservoir for the initial flush of water thus allows a rapid infiltration. The smaller pores take longer to fill and rely on capillary forces as well as gravity. The smaller pores have a slower infiltration as the terrestrial ecosystem becomes more saturated. A pore is not simply a void in the solid structure of terrestrial ecosystem. The various pore size categories have different characteristics and contribute different attributes to terrestrial ecosystems depending on the number and frequency of each type.

In conclusion, there are vast areas worldwide of polluted terrestrial ecosystems, as a consequence of a kind of agriculture prioritizing only high crop productivity. The excessive use of synthetic polluted fertilizers, systematic deforestation, terrestrial ecosystem erosion due to intensive tillage together with the action of rains or winds, loss of organic matter, and several other factors brought about increasing pollution problems. To approach the terrestrial ecosystem pollution problems, it is necessary to act on various fronts, such as characterizing hydrodynamic activity, dynamics of percolating solutions and retention of different pollutants, monitoring pollutants and augment their efficiency, assessing any changes in terrestrial ecosystem properties, evaluating quantitative and qualitative changes in terrestrial ecosystem pollutants and evaluating the impacts on terrestrial ecosystem biotas and their metabolic activities (Qin et al. 2010; Geisseler et al. 2011).

\section{Conclusion}

In this work, the importance of physical indicators for monitoring soil pollution was documented about two decades ago. A variety of physical properties have been proposed for physical monitoring purposes for soil pollution. The importance of particular physical monitoring can be inferred from the frequency of their use in various national and international programs. It should be mentioned that extensive calibration should be applied under all relevant conditions. The use of even one of the most suitable physical properties will yield only qualitative information on pollution levels.

\section{Abbreviations}

BOD: Biochemical oxygen demand; $\mathrm{CO}_{2}$ : Carbon dioxide; $\mathrm{COD}$ : Chemical oxygen demand; DO: Dissolved oxygen; $\mathrm{O}_{2}$ : Solubility of oxygen

\section{Acknowledgements}

This work was supported and funded by the National Research Centre.

\section{Authors' contributions}

MA helped determine the physical indicators of heavy metals in soil. AZ and MS helped in the relationship between the fates of pollutants in relation to soil properties. MS also revised the whole manuscript after the writing of MA and $A Z$. All authors contributed equally in the all article steps, wrote the paper, and approved the final manuscript.

\section{Authors' information}

Dr. Mohamed Saber Prof. at National Research Centre, Dokki, Giza, Department of Soil Microbiology; Agricultural and Biological Division. Dr. Mohamed AbdEl-Hady, Prof. at National Research Centre, Dokki, Giza, Department of Water Relation and Field irrigation; Agricultural and Biological Division.

Dr. Alaa Zaghloul Prof. at National Research Centre, Dokki, Giza, Soils and Water Use Department; Agricultural and Biological Division.

\section{Funding}

This work was supported and funded by the National Research Centre.

Availability of data and materials

The datasets generated and/or analyzed during the current study are included in this published.

Ethics approval and consent to participate

Not applicable.

Consent for publication

Not applicable.

\section{Competing interests}

The authors declare that they have no competing interests.

Received: 14 June 2019 Accepted: 11 July 2019

Published online: 25 July 2019

\section{References}

Beutler A, Centurion J, Souza Z, Andrioli I, Roque C (2002) Water retention in two oxisols under different uses. Revista Brasileira de Ciência do Solo 26:829-834 (in Portuguese, with abstract in English)

Bini D, Santos C, Carmo K, Kishino N, Andrade G, Zangaro W, Nogueira M (2013) Effects of land use on terrestrial ecosystem organic carbon and microbial processes associated with terrestrial ecosystem health in southern Brazil. Eur J Terrestrial Ecosystem Biol 55:117-123

Chodak M, Niklinska M (2010) Effect of texture and tree species on microbial properties of mine terrestrial ecosystems. Appl Terrestrial Ecosystem Ecol 46: 268-275

Degens B, Schipper L, Sparling G, Vojvodic-Vukovic M (2000) Decreases in organic $\mathrm{C}$ reserves in terrestrial ecosystems can reduce the catabolic diversity of 
terrestrial ecosystem microbial communities. Terrestrial Ecosystem Biol Biochem 32:189-196

Dexter A (2004) Terrestrial ecosystem physical quality part I. theory, effects of terrestrial ecosystem texture, density and organic matter, and effects on root growth. Geoderma 120:201-214

Geisseler D, Horwath W, Scow K (2011) Terrestrial ecosystem moisture and plant residue addition interact in their effect on extracellular enzyme activity. Pedobiologia 54:71-78

Hasan A, Lee KH, Azamathulla HM, Ghani AA (2011) Flow simulation for Lake Harapan using CCHE2D - a case study. Int J Model Simul 31:85-89

Preston S, Wirth S, Ritz K, Griffiths B, Young IM (2001) The role played by microorganisms in biogenesis of terrestrial ecosystem cracks: importance of substrate quantity and quality. Terrestrial Ecosystem Biol Biochem 33:18511858

Qin S, Hu C, He X, Dong W, Cui J, Wang Y (2010) Terrestrial ecosystem organic carbon, nutrients and relevant enzyme activities in particle-size fractions under conservational versus traditional agricultural management. Appl Terrestrial Ecosystem Ecol 45:152-159

Schoenholtz SH, Vam Miegroet H, Burger JA (2000) A review of chemical and physical properties as indicators of forest terrestrial ecosystem quality: challenges and opportunities. For Ecol Manag 138:335-356

Six J, Bossuyt H, Degryze S, Denef K (2004) A history of research on the link between (micro) aggregates, terrestrial ecosystem biota, and terrestrial ecosystem organic matter dynamics. Terrestrial Ecosystem Tillage Res 79:7-31

Tejada M, Garcia C, Gonzalez JL, Hernandez MT (2006) Organic amendment based on fresh and composted beet vinasse: influence on physical, chemical and biological properties and wheat yield. Terrestrial Ecosystem Sci Soc Am J 70:900-908

\section{Publisher's Note}

Springer Nature remains neutral with regard to jurisdictional claims in published maps and institutional affiliations.

\section{Submit your manuscript to a SpringerOpen ${ }^{\circ}$ journal and benefit from:}

- Convenient online submission

- Rigorous peer review

- Open access: articles freely available online

- High visibility within the field

- Retaining the copyright to your article

Submit your next manuscript at $\boldsymbol{\nabla}$ springeropen.com 